\title{
Commentary: Open versus clamp-on distal anastomosis techniques in acute type A aortic dissection: The ship has already left the port
}

\author{
Pierpaolo Chivasso, $\mathrm{MD},{ }^{\mathrm{a}}$ and Vito Domenico Bruno, $\mathrm{MD}, \mathrm{PhD}^{\mathrm{b}}$
}

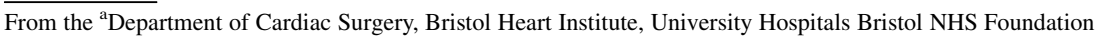
Trust, Bristol, United Kingdom; and ${ }^{\mathrm{b}}$ Bristol Medical School - Translational Health Science, University of Bristol, Bristol, United Kingdom.

Disclosures: Authors have nothing to disclose with regard to commercial support.

Received for publication Sept 25, 2018; accepted for publication Sept 26, 2018; available ahead of print Nov 7, 2018.

Address for reprints: Vito Domenico Bruno, MD, PhD, Bristol Medical School - Translational Health Sciences, University of Bristol Research Floor Level 7, Bristol Royal Infirmary, Upper Maudlin St, BS2 8HW Bristol, United Kingdom (E-mail: Vito.D.Bruno@bristol.ac.uk).

J Thorac Cardiovasc Surg 2019;157:1761-2

$0022-5223 / \$ 36.00$

Copyright (C) 2018 by The American Association for Thoracic Surgery

https://doi.org/10.1016/j.jtcvs.2018.09.100
}

In the present issue of the Journal, Geirsson and colleagues ${ }^{1}$ present the outcomes of the open-distal versus clamp-on technique from the Nordic Consortium for Acute Type A Aortic Dissection database including more than 1000 patients, with 153 of them operated with the clamp on. The authors had to compare 2 groups with numerous differences in the preoperative and operative characteristics: for certain aspects, one could argue that they are not comparable at all. When facing this situation, the use of propensity score (PS) methods appears to be a sensible option, and not surprisingly PS is increasingly used in observational cardiovascular studies. ${ }^{2}$ When using a PS method, 2 conditions must hold: the first assumption implies that all the variables affecting treatment assignment and outcome have been measured ("no unmeasured confounders assumption"); the second assumption indicates that every subject has a nonzero probability to receive either treatment. ${ }^{3}$ In this study, there was a risk of violation of these assumptions because of the nature of the disease and the related impact on the surgical treatment chosen. Instead of a PS method, the authors used a multivariable adjusted modeling approach: this approach might be considered "old fashioned" but is not necessarily inferior to PS methods ${ }^{2}$ and in certain cases is even better.

With their analysis, Geirsson and colleagues ${ }^{1}$ have shown that the use of open-distal anastomosis is associated with better short- and mid-term survivals. In an adjusted multivariable Cox model, open distal was a protective factor (hazard ratio, 0.36 ; 95\% confidence interval, 0.15-0.82). Interestingly, open-distal anastomosis was associated with higher rates of postoperative complications, especially cerebrovascular accidents. However, as noted by the authors, some of the difference observed could be explained by higher rates of intraoperative and

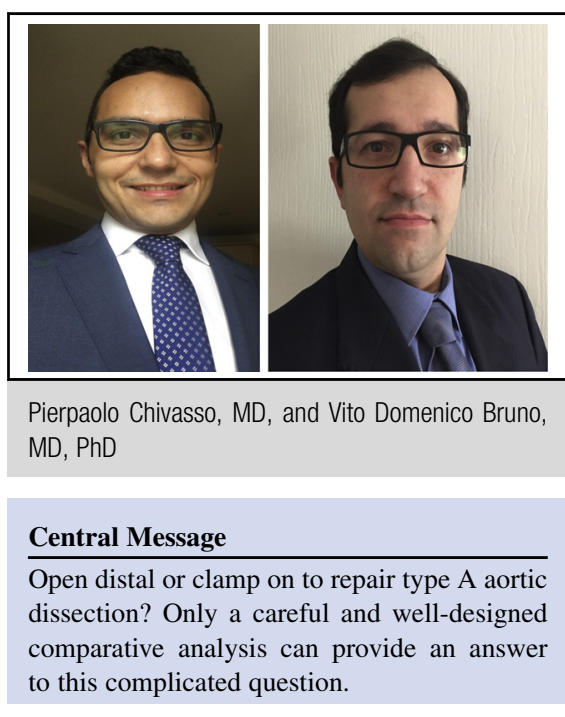

See Article page 1750. earlier death in the clamp group, thereby excluding specific complications before death. Another important finding is related to the fact that the use of the opendistal technique increased over the study period, and higher-volume hospitals used the open-distal technique more commonly than lower-volume hospitals. In the contemporary era, there is growing consensus that the distal anastomosis should be performed using the opendistal technique because of a better visualization of the dissected aorta, proper exclusion of the false lumen, and possibility of inspecting and identifying intimal tears in the arch. ${ }^{4}$ Moreover, the natural history of aortic dissection teaches us that in most cases there is a distal progression of the aortic disease that often requires further surgical or endovascular treatments. Considering this, increasing the extent of aortic replacement during the first operation, such as performing a total arch replacement with the frozen elephant trunk technique, may improve the outcomes, reducing the probability of a second surgery. ${ }^{5}$ Furthermore, the new standardized techniques of cerebral protection together with the increasing enrollment of the right axillary artery as the site of arterial cannulation have shown significant reduction of postoperative strokes compared with the more traditional deep hypothermic circulatory arrest without any cerebral protection. ${ }^{6}$ 
The idea of specialized centers with a high volume of aortic surgery to treat acute aortic syndrome is now becoming paramount. There is a large consensus that patients affected by acute aortic syndromes may benefit from treatment at dedicated specialized aortic centers with significantly improved outcomes and decreased mortality. ${ }^{7}$ Patients undergoing emergency repair of acute aortic dissection by lower-volume surgeons and centers have approximately double the risk-adjusted mortality of patients undergoing repair by the highest volume care providers. $^{8}$ Although the present study suggests that in selected circumstances, such as in very sick patients or at lower-volume hospitals, the clamp-on technique can be used with acceptable results, we think that the future treatment of acute type A aortic dissection is going toward an open-distal approach with standardized cerebral protection that should more and more be delivered by specialist aortic centers with expertise in this technique. At this stage, the ship has already left the port, and there is only marginal room for a way back.

\section{References}

1. Geirsson A, Shioda K, Olsson C, Ahlsson A, Gunn J, Hansson EC, et al. Differential outcomes of open and clamp-on distal anastomosis techniques in acute type A aortic dissection. J Thorac Cardiovasc Surg. 2019;157:1750-8.

2. Elze MC, Gregson J, Baber U, Williamson E, Sartori S, Mehran R, et al. Comparison of Propensity score methods and covariates adjustment: evaluation in 4 cardiovascular studies. J Am Coll Cardiol. 2017:69:345-57.

3. Austin PC. An introduction to propensity score methods for reducing the effects of confounding in observational studies. Multivariate Behav Res. 2011;46:399-424.

4. Conway BD, Stamou SC, Kouchoukos NT, Lobdell KW, Khabbaz KR, Murphy E, et al. Improved clinical outcomes and survival following repair of acute type A aortic dissection in the current era. Interact Cardiovasc Thorac Surg. 2014;19: 971-7.

5. Sun LZ, Qi RD, Zhu JM, Liu YM, Zheng J. Total arch replacement combined with stented elephant trunk: a new standard therapy for type A dissection involving repair of the aortic arch. Circulation. 2011;123:971-8.

6. Conzelmann LO, Weigang E, Mehlhorn U, Abugameh A, Hoffmann I, Blettner M, et al. Mortality in patients with acute aortic dissection type A: analysis of pre- and intraoperative risk factors from the German Registry for Acute Aortic Dissection Type A (GERAADA). Eur J Cardiothorac Surg. 2016;49:e44-52.

7. Mariscalco G, Maselli D, Zanobini M, Ahmed A, Bruno VD, Benedetto U, et al. Aortic centres should represent the standard of care for acute aortic syndrome. Eur J Prev Cardiol. 2018;25(1_suppl):3-14.

8. Chikwe J, Cavallaro P, Itagaki S, Seigerman M, Diluozzo G, Adams DH. National outcomes in acute aortic dissection: influence of surgeon and institutional volume on operative mortality. Ann Thorac Surg. 2013;95:1563-9. 